\title{
Implementation of aerosol-cloud interactions in the regional atmosphere-aerosol model COSMO-MUSCAT(5.0) and evaluation using satellite data
}

\author{
Sudhakar Dipu ${ }^{1}$, Johannes Quaas ${ }^{1}$, Ralf Wolke ${ }^{2}$, Jens Stoll ${ }^{2}$, Andreas Mühlbauer ${ }^{3}$, Odran Sourdeval ${ }^{1}$, \\ Marc Salzmann ${ }^{1}$, Bernd Heinold ${ }^{2}$, and Ina Tegen ${ }^{2}$ \\ ${ }^{1}$ Institute for Meteorology, Universität Leipzig, Leipzig, Germany \\ ${ }^{2}$ Leibniz Institute for Tropospheric Research, Leipzig, Germany \\ ${ }^{3}$ FM Global Research, Norwood, MA, USA
}

Correspondence to: Sudhakar Dipu (dipu.sudhakar@uni-leipzig.de)

Received: 13 July 2016 - Discussion started: 25 August 2016

Revised: 27 April 2017 - Accepted: 4 May 2017 - Published: 20 June 2017

\begin{abstract}
The regional atmospheric model Consortium for Small-scale Modeling (COSMO) coupled to the Multi-Scale Chemistry Aerosol Transport model (MUSCAT) is extended in this work to represent aerosol-cloud interactions. Previously, only one-way interactions (scavenging of aerosol and in-cloud chemistry) and aerosol-radiation interactions were included in this model. The new version allows for a microphysical aerosol effect on clouds. For this, we use the optional two-moment cloud microphysical scheme in COSMO and the online-computed aerosol information for cloud condensation nuclei concentrations $\left(C_{\mathrm{ccn}}\right)$, replacing the constant $C_{\mathrm{ccn}}$ profile. In the radiation scheme, we have implemented a droplet-size-dependent cloud optical depth, allowing now for aerosol-cloud-radiation interactions. To evaluate the models with satellite data, the Cloud Feedback Model Intercomparison Project Observation Simulator Package (COSP) has been implemented. A case study has been carried out to understand the effects of the modifications, where the modified modeling system is applied over the European domain with a horizontal resolution of $0.25^{\circ} \times 0.25^{\circ}$. To reduce the complexity in aerosol-cloud interactions, only warm-phase clouds are considered. We found that the online-coupled aerosol introduces significant changes for some cloud microphysical properties. The cloud effective radius shows an increase of $9.5 \%$, and the cloud droplet number concentration is reduced by $21.5 \%$.
\end{abstract}

\section{Introduction}

The quantification of aerosol-cloud interactions in models continues to be a challenge (IPCC, 2013). Estimates of effective radiative forcing and assessments of the radiative effects due to aerosol-cloud interactions to a large extent rely on numerical modeling. A large effort has been made to represent such effects in general circulation models (GCMs) (Penner et al., 2006; Quaas et al., 2009; Ghan et al., 2016). However, GCMs do not resolve the processes relevant for cloud dynamics well. Improving the understanding of processes of aerosol-cloud interactions thus largely relies on simulations with cloud-resolving models and large-eddy simulations (LESs) (Ackerman et al., 2000, 2004; Xue and Feingold, 2006; Sandu et al., 2008; Seifert et al., 2015; Berner et al., 2013). However, LESs often focus on case studies and use idealized boundary conditions as well as an idealized representation of the aerosol. This leads to uncertainties specifically because, when analyzing cloud systems or cloud regimes, rather than individual clouds, aerosolcloud-precipitation interaction processes often are buffered (Stevens and Feingold, 2009). Regional climate modeling is a powerful tool to overcome these limitations of smalldomain idealized LESs, and much higher resolutions are possible than for GCMs. Compared to an LES that only simulates individual cloud systems, regional climate models are able to simulate the feedbacks between clouds and aspects of the large-scale circulation and its variability reasonably well. Even though regional models do not describe part of 
the large-scale feedbacks, they may be considered a good optimal compromise (Bangert et al., 2011; Van den Heever and Cotton, 2007; Chapman et al., 2009; Forkel et al., 2015; Yang et al., 2012). A still often applied cloud microphysics parameterization in numerical weather prediction is a bulk one-moment scheme (Kessler, 1969; Lin et al., 1983) which uses the specific masses for different hydrometeor species as prognostic variables. However, it cannot treat aerosol-cloud interactions because it calculates only one moment of the size distribution and does not carry information about size or number concentration of cloud droplets. In contrast, bin microphysical schemes numerically resolve the size spectrum and are thus able to predict the spatiotemporal behavior of a number of size categories for each hydrometeor type explicitly (Khain et al., 2000; Simmel et al., 2015). However, this approach is numerically very expensive especially when applied for regional atmospheric models. As a compromise between these two approaches, two-moment microphysical schemes can predict the number concentration of the liquid and ice hydrometeors in addition to mass variables (Cotton et al., 1986; Meyers et al., 1997; Seifert and Beheng, 2006). Furthermore, numerous studies have shown that using twomoment schemes is a promising avenue in future operational forecast models (Reisner et al., 1998; Tao et al., 2003; Seifert and Beheng, 2006) and is also computationally efficient.

At present, several weather prediction and global models apply with two-moment cloud microphysical schemes. For example, the Weather Research and Forecasting (WRF) model is available with different types of two-moment microphysical schemes (Thompson et al., 2008; Morrison and Gettelman, 2008; Lim and Hong, 2010). Morrison et al. (2009) showed that using a two-moment scheme in the WRF model produced more trailing stratiform precipitation in an idealized two-dimensional squall case, which is more consistent with observations. In another study, Li et al. (2008) investigated the effect of aerosol on cloud microphysical processes with a two-moment microphysical scheme in the WRF model. Also, Lim and Hong (2010) have included a prognostic equation for cloud water and cloud condensation nuclei number concentration $\left(C_{\mathrm{ccn}}\right)$, which could reduce the uncertainty in investigating the aerosol effect on cloud properties and the precipitation process in the WRF model. Seifert et al. (2012) and Weverberg et al. (2014) compared the operational one-moment and two-moment microphysical schemes in the Consortium for Small-Scale Modeling atmospheric model (COSMO). Further, some groups previously implemented aerosol-cloud interactions in COSMO, albeit with a different aerosol scheme (Bangert et al., 2011; Zubler et al., 2011; Possner et al., 2015) and very few are coupled to the radiation scheme. Seifert et al. (2012) compared the operational one-moment microphysics scheme to a two-moment scheme. They found that aerosol perturbation has a significant effect on radiation and near-surface temperature, rather than the resulting surface precipitation.
In this paper, we discuss the improved cloud microphysics parameterization in the COSMO model (Doms and Schättler, 1999) via the online-coupled aerosol model, Multi-Scale Chemistry Aerosol Transport (MUSCAT; Wolke et al., 2004, 2012). The two-moment cloud microphysical scheme in the COSMO model (Seifert and Beheng, 2006) uses fixed profiles of $C_{\mathrm{ccn}}$. Rather than this simplification, here we use $C_{\text {ccn }}$ predicted on the basis of the simulated aerosol from the MUSCAT module. This will enable the COSMO model to have temporally and spatially varying $C_{\mathrm{ccn}}$ values at each grid point, which are fully consistent with the cloud and precipitation fields, as well as with dynamics (e.g., scavenging is taken into account, as is vertical transport) to represent aerosol-cloud interactions. In two further steps, (i) the radiation scheme is slightly revised to consider the cloud droplet size information (so far considered constant even when applying the two-moment cloud microphysical scheme) and (ii) a diagnostic tool, the Cloud Feedback Model Intercomparison Project Observational Simulator Package (BodasSalcedo et al., 2011, 2008; Nam and Quaas, 2012) is implemented, which allows for a consistent evaluation using satellite observations. The paper is organized as follows: Sect. 2 gives a brief introduction to the coupled model system of COSMO-MUSCAT, data, and methodology. The comparison between the improved two-moment cloud microphysical parameterization with the available two-moment scheme making use of the COSP satellite simulator is discussed in Sect. 3. Finally, concluding remarks are found in Sect. 4.

\section{Data and methodology}

\subsection{The COSMO-MUSCAT model and revised cloud activation}

The non-hydrostatic three-dimensional model, COSMO, which was originally developed for limited-area operational numerical weather predictions (NWPs), is used in this study (Doms and Schättler, 1999; Steppeler et al., 2003). This model has been used operationally in convection-permitting configurations since 2007 by the German Weather Service (Deutscher Wetterdienst, DWD; Baldauf et al., 2011). In this study, we have used COSMO version 5.0, which is initialized and forced by reanalyzed data provided by the global meteorological model GME (Global Model of the Earth) of DWD, which is a hydrostatic weather prediction model (Majewski et al., 2002). GME operates on an icosahedralhexagonal grid having a horizontal resolution of approximately $40 \mathrm{~km}$ and vertical resolution of 40 layers up to $10 \mathrm{hPa}$. The COSMO model is initialized with the interpolated GME initial state and nested within GME with hourly updates of lateral boundary values. In this study, the COSMO model has been configured in a non-convection-permitting mode with a uniform horizontal grid resolution of $0.25^{\circ}$ $(\approx 28 \mathrm{~km})$. The two-moment cloud microphysics scheme in 
the COSMO model (Seifert and Beheng, 2006) distinguishes between five hydrometeor classes, namely cloud droplets, rain, ice crystals, snow, and graupel. Processes in the warm (liquid) phase considered by this scheme include the nucleation of cloud droplets, autoconversion of cloud droplets to form rain, accretion, and self-collection of rain droplets. The formulations have been derived by Seifert and Beheng (2001) from the theoretical formulation of Beheng and Doms (1986). However, the radiation scheme does not yet make use of the additional information about cloud particle sizes provided by the two-moment microphysics. It uses the Ritter and Geleyn (1992) parameterization for the cloud optical properties in radiation scheme. According to Ritter and Geleyn (1992), the cloud optical properties are approximated by the relation between specific liquid water content $q_{\mathrm{c}}$ and cloud effective radius $r_{\mathrm{e}}$. Thus, cloud optical depth $\tau_{\mathrm{c}}$ is expressed as

$\tau_{\mathrm{c}}=\left(c_{1}+\frac{c_{2}}{r_{\mathrm{e}}}\right) q_{\mathrm{c}} \mathrm{d} z$

where $\mathrm{d} z$ is layer thickness, and $c_{1}$ and $c_{2}$ are constants. Similarly, the effective radius $r_{\mathrm{e}}$ is related to specific cloud water content and is approximated as

$r_{\mathrm{e}}=c_{3}+c_{4} q_{\mathrm{c}}$,

where $c_{3}$ and $c_{4}$ are constants (Ritter and Geleyn, 1992). In order to take the two-moment microphysics into account in the radiation scheme, the cloud optical properties have to be modified. The cloud effective radius $r_{\mathrm{e}}$ is derived by dividing the third and second moments of the size distribution (Martin et al., 1994; Morrison and Gettelman, 2008) which, after rearranging, yield

$r_{\mathrm{e}}=\frac{\Gamma(\mu+4)}{2 \lambda \Gamma(\mu+3)}$,

where $\mu$ is the spectral shape parameter (here, $\mu=2$ ), $\Gamma$ is the gamma distribution function, and $\lambda$ is the slope parameter, which is given by

$\lambda=\left[\frac{\pi \rho_{\mathrm{w}} N_{\mathrm{d}} \Gamma(\mu+4)}{6 \rho q_{\mathrm{c}} \Gamma(\mu+1)}\right]^{\frac{1}{3}}$,

where $\rho$ is the density of the air, $\rho_{\mathrm{w}}=1000 \mathrm{~kg} \mathrm{~m}^{-3}$ is the bulk density of liquid water, $N_{\mathrm{d}}$ is the droplet number concentration, and $q_{\mathrm{c}}$ is the specific water content. The corresponding cloud optical depth is given by

$\tau_{\mathrm{c}}=\frac{3 \rho q_{\mathrm{c}} \mathrm{d} z}{2 \rho_{\mathrm{w}} r_{\mathrm{e}}}$,

where $\mathrm{d} z$ is the layer thickness, $\rho_{\mathrm{w}}$ is the bulk density of liquid water, and the droplet size spectrum is considered vertically constant in the grid layer.

The online-coupled model system of COSMO-MUSCAT (Wolke et al., 2004, 2012; Renner and Wolke, 2010) is used for prognostic cloud condensation nuclei in the cloud microphysics parameterization in the COSMO model. The chemistry-aerosol transport model MUSCAT treats atmospheric transport as well as chemical reactions with the Regional Atmospheric Chemistry Mechanism (RACM; Stockwell et al., 1997). In MUSCAT, all meteorological fields are given with respect to the uniform horizontal meteorological grid from the online-coupled COSMO2M (COSMO with two-moment scheme) model, whereas the aerosol information is fed back to the COSMO2M model from MUSCAT. In the previous setting, the interactions only considered the radiative effects of aerosols (scattering and absorption of solar radiation), as well as the scavenging of aerosol and in-cloud aerosol chemistry. A diagram illustrating the COSMO-MUSCAT modeling setup is shown in Fig. 1. In the COSMO model with the two-moment approach, the nucleation of cloud droplets has been treated explicitly and the aerosol activation parameterization is based on empirical activation spectra, which is in the form of the following power law:

$N_{\mathrm{ccn}}=C_{\mathrm{ccn}} S^{k}, \quad S$ in $\%$,

where $S$ is supersaturation, $C_{\mathrm{ccn}}=1.26 \times 10^{9} \mathrm{~m}^{-3}$, and $k=$ 0.308 for continental conditions or $C_{\mathrm{ccn}}=1.0 \times 10^{8} \mathrm{~m}^{-3}$ and $k=0.462$ for maritime conditions (Khain et al., 2001). Seifert et al. (2012) investigated the influence of substantially perturbing $C_{\mathrm{ccn}}$ from 100 to $3200 \mathrm{~cm}^{-3}$ (see above for a brief discussion of this paper). Accordingly, the grid-scale explicit nucleation rate is calculated from the time derivative of the activation relation (Seifert and Beheng, 2006):

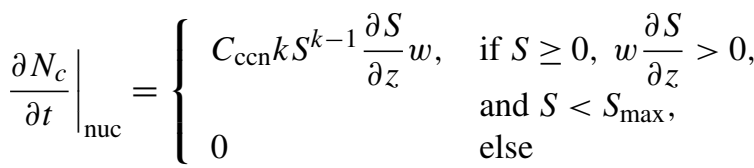

The above parameterization scheme uses constant $C_{\mathrm{ccn}}$, and $S_{\max }$ varies with atmospheric conditions (in maritime conditions, $C_{\mathrm{ccn}}$ assumes that at $S_{\mathrm{max}}=1.1 \%$, all $C_{\mathrm{ccn}}$ are already activated). In the above equation, nucleation explicitly depends on grid-scale supersaturation in combination with saturation adjustment assumed in the cloud scheme, which has limitations (Seifert and Beheng, 2006). As an initial step, a coupled model simulation is carried out by setting $S_{\max }=2.0 \%$, the condition for intermediate aerosols in the COSMO model. In a second step, we have used simulated sulfate $\left(\mathrm{SO}_{4}\right)$ aerosol mass concentration information from the MUSCAT model. The emission inventory in the MUSCAT model is provided by the TNO (Netherlands Organisation for Applied Scientific Research) for the Air Quality Model Evaluation International Initiative (AQMEII) project (Pouliot et al., 2012). $C_{\mathrm{ccn}}$ is derived using the following empirical relation (Boucher and Lohmann, 1995):

$C_{\mathrm{ccn}}=10^{2.21+0.41 \log \left(m \mathrm{SO}_{4}\right)}$, 


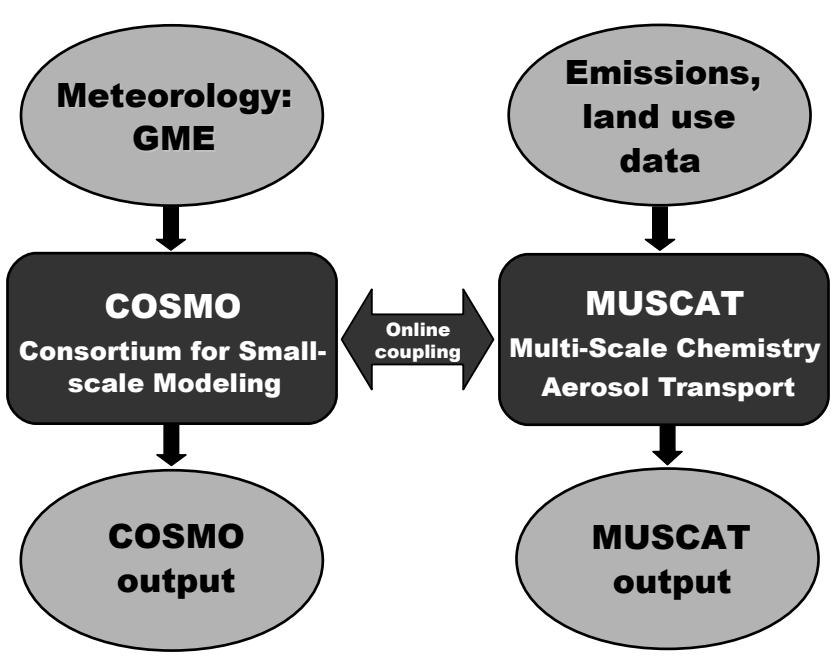

Figure 1. COSMO-MUSCAT modeling system. Left-hand side: setup of the COSMO modeling system with GME input. Right-hand side: MUSCAT modeling system with land use and emissions.

where $m \mathrm{SO}_{4}$ is the sulfate aerosol mass concentration in $\mu \mathrm{g} \mathrm{m}^{-3}$. The constant $C_{\text {ccn }}$ in Eq. (7) is replaced by the spatially and temporally varying $C_{\mathrm{ccn}}$ values, derived from Eq. (8), using the sulfate aerosol mass concentration from the MUSCAT module. This empirical relationship which links sulfate aerosol mass concentration to $C_{\mathrm{ccn}}$ is subject to substantial uncertainty. Representing sulfate aerosol as a surrogate for all aerosols is probably too simplistic to capture the complexity of the whole activation process. Future work will introduce a more complex aerosol-cloud coupling, taking into account also other aerosol compounds. The Seifert and Beheng (2006) cloud microphysical scheme considers both phases. Also, mixed-phase clouds are affected by the revision of the $\mathrm{CCN}$ parameterization, e.g., via the BergeronFindeisen process. Nevertheless, the current analysis focuses on the liquid phase only; investigations on mixed and icephase clouds are left for future research.

\subsection{Model evaluation method}

Satellite retrievals have been used to evaluate the performance of the numerous GCMs and NWP models (e.g., Quaas et al., 2004, 2009; Zhang et al., 2005; Brunke et al., 2010; Cherian et al., 2012; Nam et al., 2014). However, a meaningful evaluation of modeling with satellite observations is challenging because of the difference in the model variables and the satellite retrievals. To address this problem, the integrated satellite simulator Cloud Feedback Model Intercomparison Project (CFMIP) Observation Simulator Package (COSP; Bodas-Salcedo et al., 2011) has been developed. The COSP satellite simulator produces model diagnostics which are fully consistent with satellite products such as the International Satellite Cloud Climatology Project (ISCCP; Rossow and Schiffer, 1999), Moderate Resolution Imaging
Spectroradiometer (MODIS; Platnick et al., 2003; Pincus et al., 2012), Cloud-Aerosol Lidar and Infrared Pathfinder Satellite Observation (CALIPSO; Chepfer et al., 2010), and the CloudSat cloud radar (Marchand et al., 2009). To produce similar output to satellite data, COSP requires the grid mean vertical profile of temperature, humidity, hydrometer mixing ratios, cloud optical thickness and emissivity, the surface temperature, and emissivity from the model. It produces output comparable with satellite data in three steps. First, it addresses the mismatch between model and satellite pixel resolution by generating subcolumns using model information about subgrid-scale variability, e.g., from the assumption on vertical overlap of fractional cloudiness. Second, vertical profiles of individual subcolumns are passed to each instrument simulator. Lastly, the COSP statistic module gathers the output from all instrument simulators (Bodas-Salcedo et al., 2011). COSP is implemented online in the COSMO model with hourly output. While using COSP facilitates a more consistent comparison between model output and satellite data, differences between the model simulation and the satellite can, for example, still arise due to displacements in simulated storm tracks. COSP has previously been used with COSMO by Mühlbauer et al. (2014, 2015). The output diagnostics include a variety of cloud properties, which facilitate consistent model-to-observation comparisons as well as consistent intermodel comparisons.

In the next section, we evaluate the model results (derived using MODIS and the ISCCP satellite simulators) with MODIS level-2 and ISCCP satellite observations, in terms of cloud optical and microphysical properties (cloud optical depth, effective radius, liquid water path, and cloud fraction). The MODIS satellite simulator uses profiles of particle size for liquid and ice and corresponding optical depths within each layer of the subcolumn as a function of model levels. Using the cloud overlap assumption, 0 or 1 cloudiness in each subcolumn is created in each level. The diagnostics are then integrated over the cloudy subcolumns to obtain in-cloud average cloud optical depth and liquid water path. In turn, cloud effective radius is sampled at the cloud tops, which is not a vertical integral. Further, the ISCCP simulator aggregates pixel-scale cloud retrievals (fraction of the subcolumn with $\tau \geq 0.3$ ) to estimate cloud fraction (for more details, see Pincus et al., 2012).

The precision of weather forecasts for longer times is inherently limited by the non-linear nature of the problem. As forecast progresses, the uncertainty in weather prediction also increases. In turn, the earliest forecast time steps are still substantially affected by the initialization. Hence, we have considered the third day of the simulation for evaluating the model with satellite observations. The synoptic condition which is discussed in the next section. To compare with model simulations, different swath data sets of MODIS level2 on 17 February 2007 (daytime overpass only) are combined and gridded to the model domain and model outputs are averaged between 08:00 and 14:00 UTC (corresponding ap- 
proximately to the MODIS Terra overpass time over the domain). Also, MODIS level-2 products and model simulations are screened for liquid-phase clouds because in COSMOMUSCAT only cloud microphysics for liquid clouds were modified. Additionally, MODIS cloud optical depth and effective radius are applied with threshold values of 5 and $2 \mu \mathrm{m}$ (Sourdeval et al., 2016; Z. Zhang et al., 2012). Since the analysis is carried out for winter, satellite retrievals can be affected by snow cover on the ground. However, the MODIS retrieval (Platnick et al., 2001) uses a combination of absorbing spectral channels for which the snow/ice albedo is relatively small which makes it suitable for retrieving cloud properties over snow. Furthermore, the COSPdiagnosed model clouds are compared to ISCCP daily cloud products. For that, modeled ISCCP cloud products are regridded from 28 to $280 \mathrm{~km}$ resolution (ISCCP satellite resolution) using a grid interpolation method and averaged daily. Besides these satellite observations, Clouds and the Earth's Radiant Energy System (CERES; Loeb et al., 2012) satellite observations are also used for model evaluation, which are daily products (Kato and Loeb, 2003). One should keep in mind that the satellite products, just like models, are prone to biases. Nonetheless, the spatial correlation of the cloud structures is well represented (Noble and Hudson, 2015; Min et al., 2012).

\subsection{Numerical simulations}

To isolate and analyze the effects of the model modifications, we have performed three different model simulations with the same interpolated GME initial conditions for the time period of 10 days (15-24 February 2007). They are (a) a standard COSMO two-moment simulation with fixed $C_{\text {cen }}\left(3.0 \times 10^{8} \mathrm{~m}^{-3}\right)($ COSMO2M), (b) a COSMO twomoment simulation with radiation coupled to cloud microphysics (COSMO2MR) which uses Eqs. (3)-(5) in the radiation scheme (here, also $C_{\mathrm{ccn}}$ is kept fixed as in COSMO2M), and (c) a coupled COSMO-MUSCAT simulation, i.e., using interactive rather than prescribed $C_{\mathrm{ccn}}$ and treating radiation in the same way as COSMO2MR (COSMO-MUSCAT). In most of the discussion, we have used simulations (a) and (c). In all three model versions (COSMO2M, COSMO2MR, and COSMO-MUSCAT), we make use of the COSP diagnostics for the MODIS and ISCCP satellite simulators.

\section{Results}

\subsection{Synoptic situation}

The simulation starts on 15 February and ends on 24 February 2007. At the beginning of the simulation (00:00 UTC), the meteorological condition is dominated by a low-pressure system over the North Atlantic and a high-pressure system over land. The $2 \mathrm{~m}$ temperature shows a temperature gradient with a warm ocean and a cool continent, mostly in the northeastern part of the domain. The winds are mostly strong southwesterly over the Atlantic and northerly and northwesterly in the southern region (Fig. S1 in the Supplement). Since the case study has been conducted for 17 February, the model-derived key meteorological parameters at 12:00 UTC are illustrated in Fig. 2. On 17 February, the low-pressure system has moved to the French Atlantic coast and a cyclonic circulation has set up over the region. Furthermore, a strong high pressure is seen over northeastern Europe. The $2 \mathrm{~m}$ temperature shows that prominent winter synoptic conditions still exist in the northern part with a warm oceanic region (Atlantic) and cold northeastern part. The southern region has a maximum temperature of $20^{\circ} \mathrm{C}$, whereas the northeastern continental region experiences a minimum temperature of $-20^{\circ} \mathrm{C}$. The cyclonic circulation drives the air mass from the oceanic region and results in the formation of clouds along the frontal systems. In addition, the high pressure in the eastern part of the domain results in a cloudfree region due to subsidence. However, most of the domain is cloud covered, with cloud fraction close to $100 \%$. Furthermore, rainfall around $100 \mathrm{~mm}$ (accumulated precipitation over $96 \mathrm{~h}$ ) on 17 February is observed along with the cyclonic circulation and the southeastern part of Europe, south of the low-pressure system. The modeled convective cloud bases are located between 500 and $4000 \mathrm{~m}$ over the domain.

\subsection{Evaluation with satellite data}

The model-derived cloud fraction is averaged daily (0:00 to 24:00 UTC) to illustrate the comparison between the model (COSP) and ISCCP satellite retrievals (Fig. 3). The observed cloud fraction shows more cloud-free regions compared to the model simulations. Nevertheless, the modelderived cloud fraction is in broad agreement with ISCCP satellite retrievals, allowing now for a more detailed analysis of the cloud microphysical properties with a fine resolution which is the focus of this study. Furthermore, a comparison of radiative fluxes with CERES (Clouds and the Earth's Radiant Energy System) satellite products is discussed in Sect. 3.3.

Figure 4 shows the comparison between MODIS-retrieved (Fig. 4a-c) and COSMO-MUSCAT-simulated (Fig. 4d-f) cloud optical depth, cloud droplet effective radius, and cloud liquid water path. From the figure, it can be noticed that the simulated cloud optical depth exhibits a spatial pattern similar to the observations, albeit with higher magnitude in the MODIS level-2 retrievals (Fig. 4a and d). In the satellite retrievals, it varies between 5 and 100 and in the model between 5 and 45, with maximum values observed over similar geographical regions. However, the satellite-derived cloud optical depth and liquid water path are larger in comparison to model (COSMO-MUSCAT) outputs. The model-derived cloud effective radius exhibits both a similar spatial pattern and magnitude compared to that of the MODIS satellite retrievals (Fig. 4b and e). The modeled cloud droplet effec- 

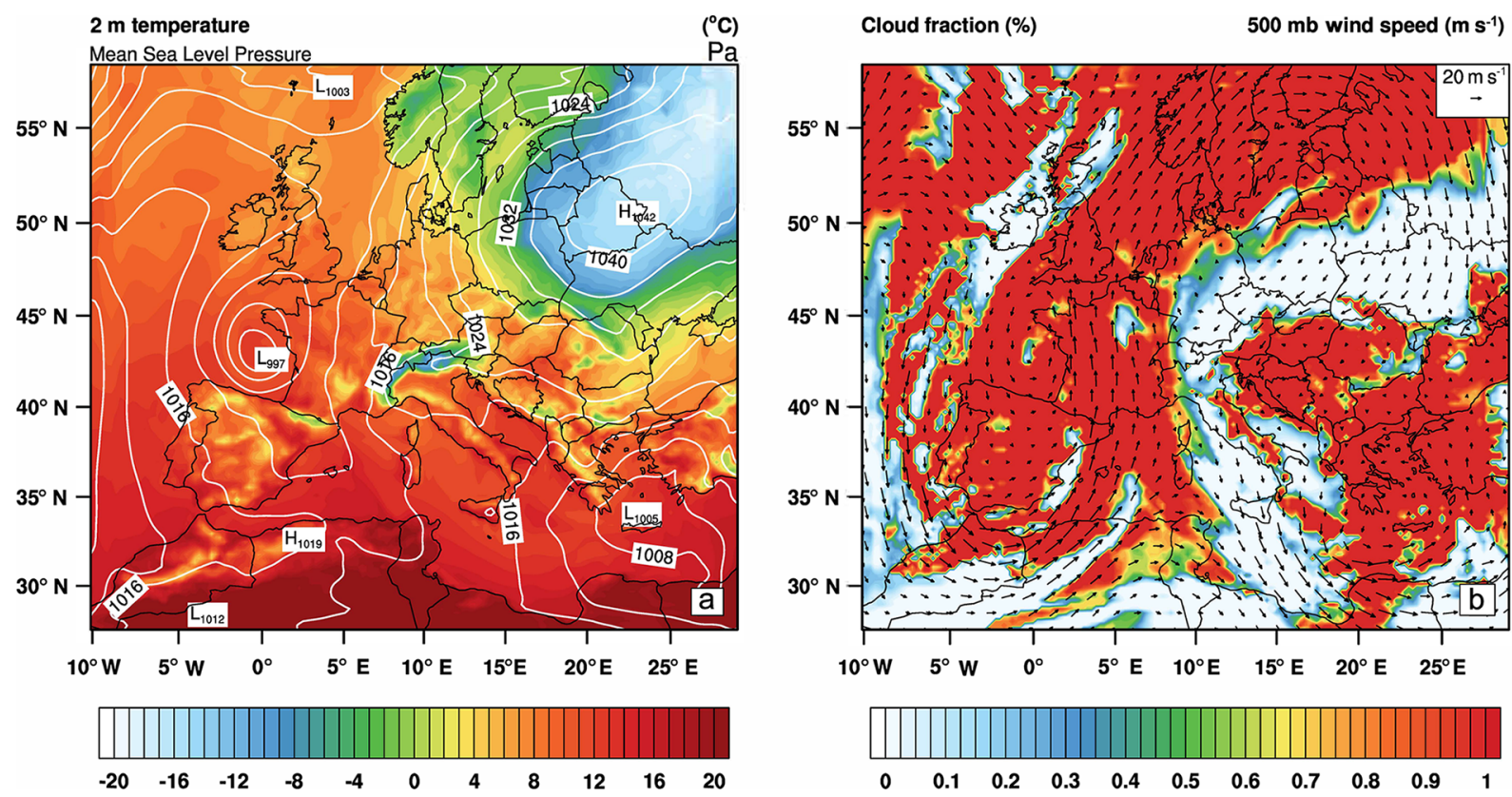

Figure 2. Model synoptic conditions for 17 February 2007 at 12:00 UTC: (a) surface pressure in contours and $2 \mathrm{~m}$ temperature $\left({ }^{\circ} \mathrm{C}\right)$ as color shading, (b) $500 \mathrm{mb}$ wind vectors and total cloud area fraction as color shading.

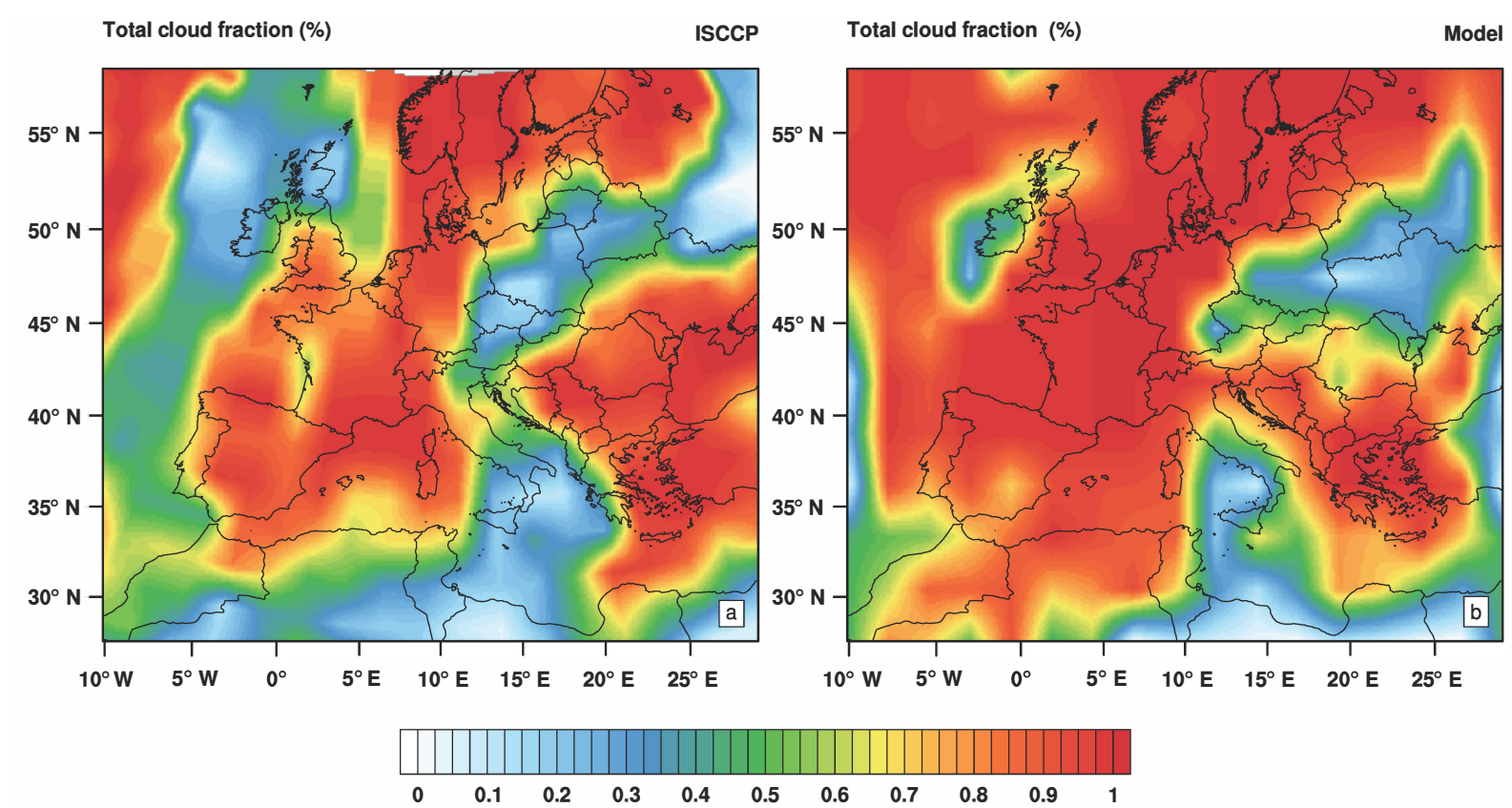

Figure 3. (a) Satellite and (b) model-derived (COSMO-MUSCAT) ISCCP cloud fraction for 17 February 2007 (averaged daily).

tive radius varies between 3 and $16 \mu \mathrm{m}$, whereas it is in the range between 2 and $30 \mu \mathrm{m}$ in the satellite retrievals. Similar to cloud optical depth, liquid water path also exhibits comparable spatial patterns for both model and observations. However, the modeled liquid water path varies between 0.025 and $0.425 \mathrm{~kg} \mathrm{~m}^{-2}$, and in the satellite observation it varies between 0.25 and $1.0 \mathrm{~kg} \mathrm{~m}^{-2}$. The white regions (missing val- ues) in satellite retrievals can be explained by the very strict quality filtering of the MODIS cloud products. The domainaveraged cloud optical depth, effective radius, and liquid water path are $23.34,11.30 \mu \mathrm{m}$, and $0.175 \mathrm{~kg} \mathrm{~m}^{-2}$, whereas the COSMO-MUSCAT-derived values are 7.60, $9.93 \mu \mathrm{m}$, and $0.056 \mathrm{~kg} \mathrm{~m}^{-2}$, which illustrates an underestimation of all simulated quantities compared to the satellite-derived cloud 

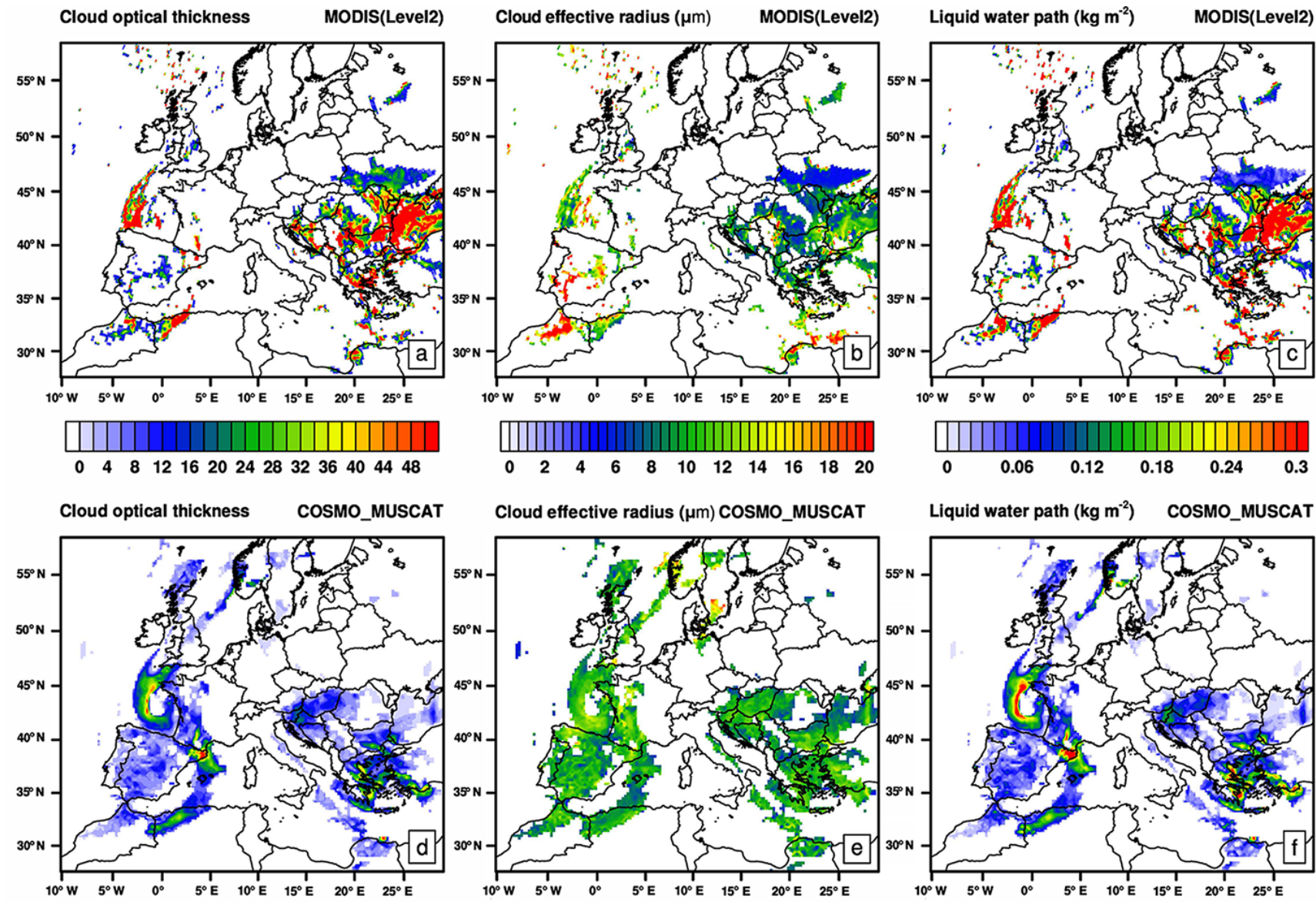

Liquid water path $\left(\mathrm{kg} \mathrm{m}^{-2}\right) \quad$ COSMO_MUSCAT
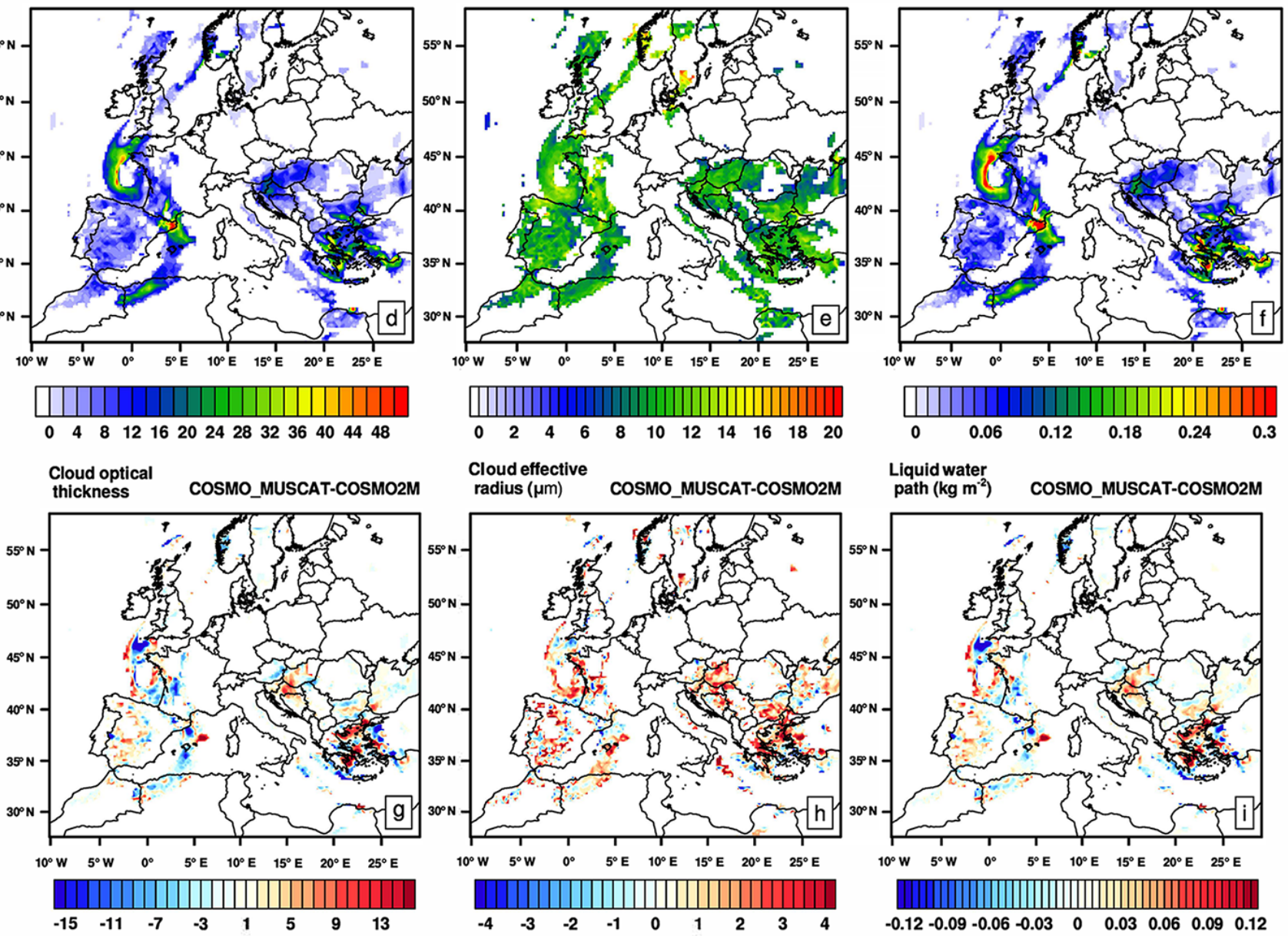

Figure 4. MODIS level-2 (a) cloud optical depth, (b) cloud effective radius, (c) COSMO-MUSCAT-derived cloud water path (averaged between 08:00 and 14:00 UTC - approximate MODIS Terra overpass time over the domain), (d) cloud optical depth, (e) cloud effective radius, (f) cloud water path, and the differences between COSMO-MUSCAT and COSMO2M simulations (g, h, i) for 17 February 2007. 

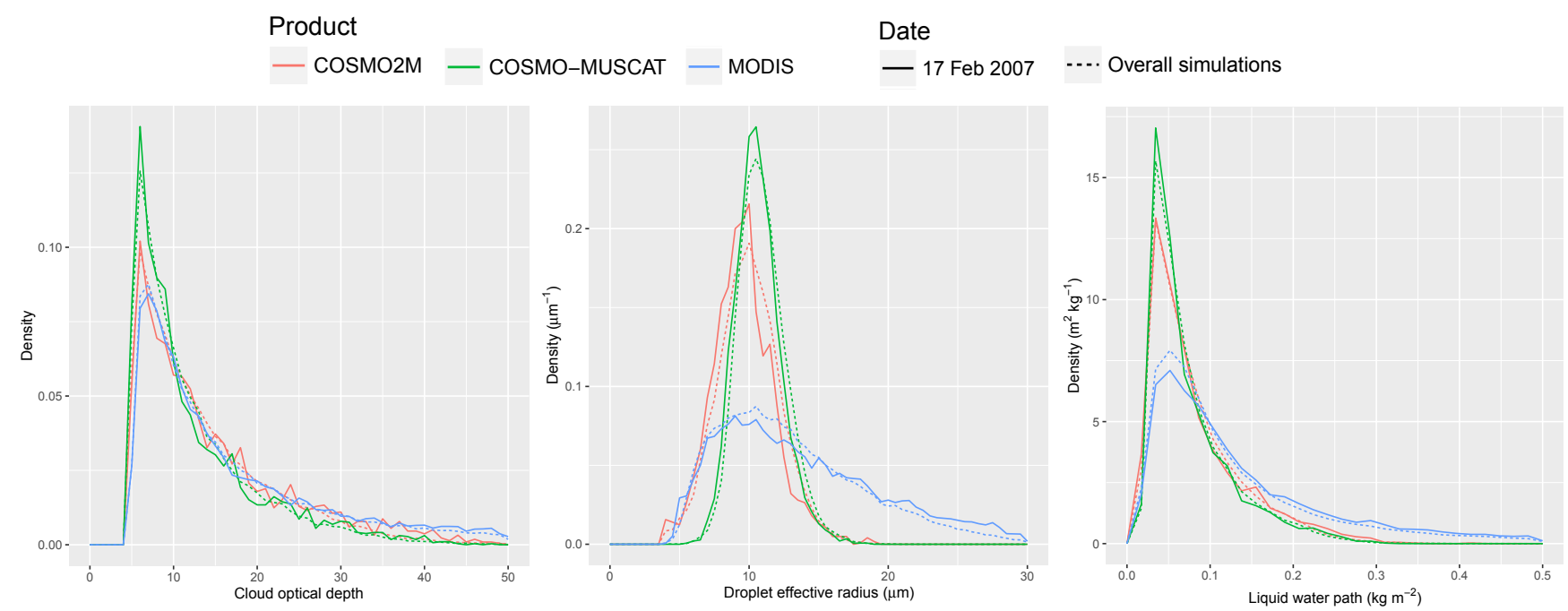

Figure 5. Probability density functions (PDFs) of cloud optical depth, cloud effective radius, liquid water path from COSMO-MUSCAT (green), COSMO2M (red), and MODIS level-2 products (blue) for 17 February 2007 (solid line) and for a 10-day (15-24 February 2007) simulation period (dashed line).

optical properties. The above cloud optical properties are calculated using Eqs. (3) and (5) in the models, although their correlations are valid only for that particular model layer/levels.

In the following, the statistical distribution of the satellite and the model cloud microphysical properties are compared and evaluated in terms of probability density functions (PDFs). Figure 5 represents the probability density function of the spatiotemporal distribution of cloud optical depth, effective radius, and liquid water path, defined as the normalized count of occurrence per bin width of cloud optical property. The cloud optical depth PDF shows that thin clouds (cloud optical depth $<10$ ) in all model versions occur substantially more frequently than in the satellite retrievals, and thick clouds (cloud optical depth $>30$ ) occur less frequently. The modeled cloud effective radius PDFs are constrained to 3 and $16 \mu \mathrm{m}$, whereas the satellite retrievals show a range of 4 to $30 \mu \mathrm{m}$. A shift of the PDF is found in the COSMO-MUSCAT-derived PDFs, which indicate the increased droplet size for the interactive $C_{\mathrm{ccn}}$. For liquid water path, modeled PDFs overestimate the clouds with low liquid water path and underestimate clouds with high water paths. The differences in PDFs largely follow what is found for the cloud optical depth, but model deficiencies compared to the satellite retrievals are substantially larger. The analysis also illustrates an increase in cloud optical PDF from the COSMO-MUSCAT simulation. Certainly, the drop and preponderance of modeled cloud optical properties can be influenced by model tuning, an approach which, however, has not been performed yet for the COSMO-MUSCAT model version.

The outcome of the cloud microphysics modifications can be analyzed by considering the difference between the two simulations (COSMO-MUSCAT and COSMO2M), which is shown in Fig. 4g-i. The version considering the interactive aerosol number concentration (COSMO-MUSCAT) exhibits an increase in the cloud droplet effective radius by a range of 1-4 $\mu \mathrm{m}$ throughout the domain with an overall increase of $9.5 \%$, although a slight reduction can be noticed in a few areas. For cloud optical depth and liquid water path, both generally show increases despite the reduction in a few areas. The revised parameterization in the coupled model has modified the spatial distribution of the cloud optical depth in the range of \pm 15 and the liquid water exhibits a variation in the range of $\pm 0.12 \mathrm{~kg} \mathrm{~m}^{-2}$. However, the domain-averaged cloud optical depth and liquid water path have been increased by 4.1 and $14.2 \%$, which is also observed in the PDF analysis.

The cloud droplet number concentration $N_{\mathrm{d}}$ can be used as a diagnostic for aerosol cloud interactions. From satellite observations, it can be expressed in terms of cloud optical depth $\tau_{\mathrm{c}}$ and effective radius $r_{\mathrm{e}}$ (Quaas et al., 2006), which are given by

$N_{\mathrm{d}}=\alpha \tau_{\mathrm{c}}^{0.5} r_{\mathrm{e}}^{-2.5}$,

where $\alpha=1.37 \times 10^{-5} \mathrm{~m}^{-0.5}$. Likewise, the model-derived $N_{\mathrm{d}}$ is also estimated using Eq. (9), which uses COSP-derived (MODIS simulator) cloud optical depth and effective radius. Figure 6a-c show the comparison between modeled (COSMO2M and COSMO-MUSCAT) and observed $N_{\mathrm{d}}$. On 17 February 2007, the domain-averaged $N_{\mathrm{d}}$ values are 153, 120 , and $378 \mathrm{~cm}^{-3}$ for COSMO2M, COSMO-MUSCAT, and MODIS, which indicates an underestimation of modelderived values (Fig. 6a-c) compared to MODIS (Y. Zhang et al., 2012; Storelvmo et al., 2009). The intermodel comparison (COSMO2M and COSMO-MUSCAT) reveals that 

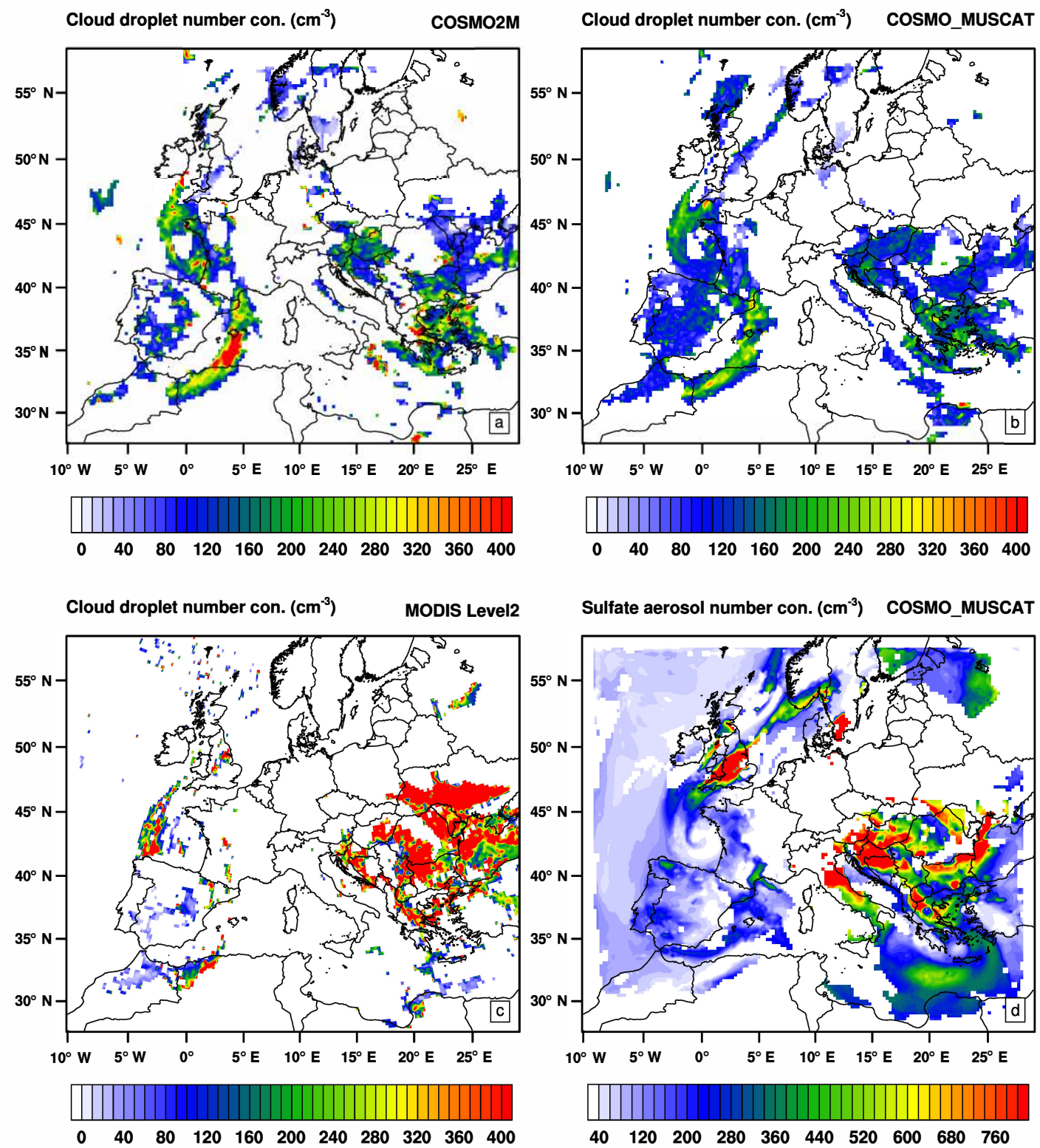

Figure 6. Cloud droplet number concentration (averaged between 08:00 and 14:00 UTC - MODIS Terra overpass time over the domain) for (a) COSMO2M, (b) COSMO-MUSCAT, (c) MODIS level-2, and (d) sulfate aerosol number concentration below the convective cloud base from the MUSCAT model for 17 February 2007.

COSMO-MUSCAT-derived $N_{\mathrm{d}}$ shows a decrease of $21.5 \%$. Figure $6 \mathrm{~d}$ shows the spatial distribution of sulfate aerosol number concentration (aerosol number concentration proxy) below the convective cloud base (representative of aerosols in the model and it is also averaged for 8-14 $\mathrm{h}$ on 17 February 2007), where high number concentrations are simulated over southeastern Europe. In contrast, $N_{\mathrm{d}}$ values are smaller over the same region. This is because the models with Boucher and Lohmann (1995) parameterization saturate $N_{\mathrm{d}}$ over high aerosol or polluted regions (Penner et al., 2001), and the high pressure in this region results in trapping aerosol in the boundary layer. From the above analysis, it can be inferred that COSMO-MUSCAT can be used as a tool for regional aerosol-cloud interaction estimates. The interactive aerosol coupling results show an increase in cloud droplet effective radius by $9.5 \%$ and a reduction in $N_{\mathrm{d}}$ by $21.5 \%$.

\subsection{Impact on radiative balance}

In addition, we have also implemented aerosol-cloudradiation interactions in the COSMO model by revising the radiation scheme to make use of a droplet-size-dependent cloud optical depth. Incorporating aerosol-cloud-radiation 

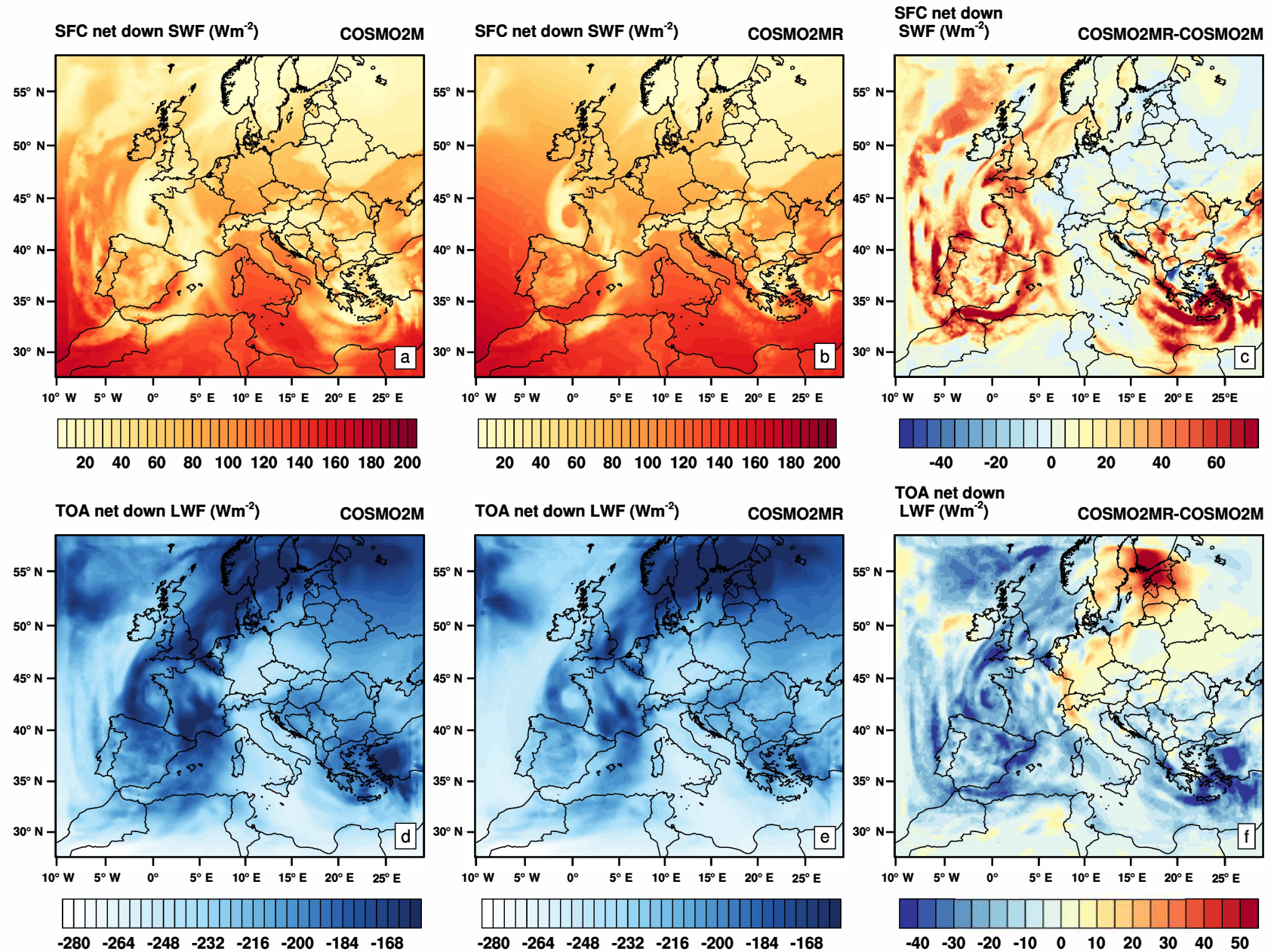

Figure 7. Comparison and difference between shortwave and longwave radiation fluxes at the surface and top of the atmosphere, and the difference between the two simulations (COSMO2MR radiation coupled minus COSMO2M).

interactions in the model causes a significant change in the radiation fluxes. Figure 7 shows the spatial distribution of net downward shortwave flux at the surface, net downward longwave flux at the top of the atmosphere (TOA), and the corresponding difference between COSMO2M and COSMO2MR simulations (with fixed $C_{\mathrm{ccn}}$ ). Similar to the above analysis, we have compared daily averaged fluxes for 17 February 2007. The figure shows that, in the radiation-modified version (COSMO2MR), there is an increase in the net downward shortwave flux at the surface. Likewise, an overall reduction is observed in the net downward longwave flux at the TOA despite the increase in the northeast part of the domain. The net downward shortwave radiation at the surface shows an increase of about 10 to $60 \mathrm{~W} \mathrm{~m}^{-2}$ and the net downward longwave flux shows a decrease of 10 to $40 \mathrm{~W} \mathrm{~m}^{-2}$. This illustrates the reduction of cloud cover in the COSMO2MR simulations, which implies that reduced cloud cover results in more shortwave radiation reaching the surface and less longwave radiation reflected back to TOA. This can be in- ferred by considering the cloud optical depth and liquid water path difference between the COSMO2M and COSMO2MR simulations, which are also averaged daily (Fig. 8). From the figure, the regions with reduced cloud optical depth and liquid water path are correlated with increased net shortwave flux at the surface and decreased net longwave flux at the TOA. To illustrate the combined effect of the revised radiation scheme and interactive aerosols, COSMO-MUSCATderived radiative fluxes are compared to CERES satellite observations (Kato and Loeb, 2003; Loeb et al., 2012). For comparison, we have considered computed CERES fluxes (derived based on state and composition of the atmosphere, surface, and the incoming solar radiation) with spatial resolution $1^{\circ} \times 1^{\circ}$, and care must be taken while interpreting the results. Also, during winter, the uncertainty in CERES flux observations is slightly higher (Guo et al., 2007). The spatial pattern and the magnitude of model-simulated fluxes are comparable to satellite observations in which the surface net downward shortwave flux ranges between 20 and 


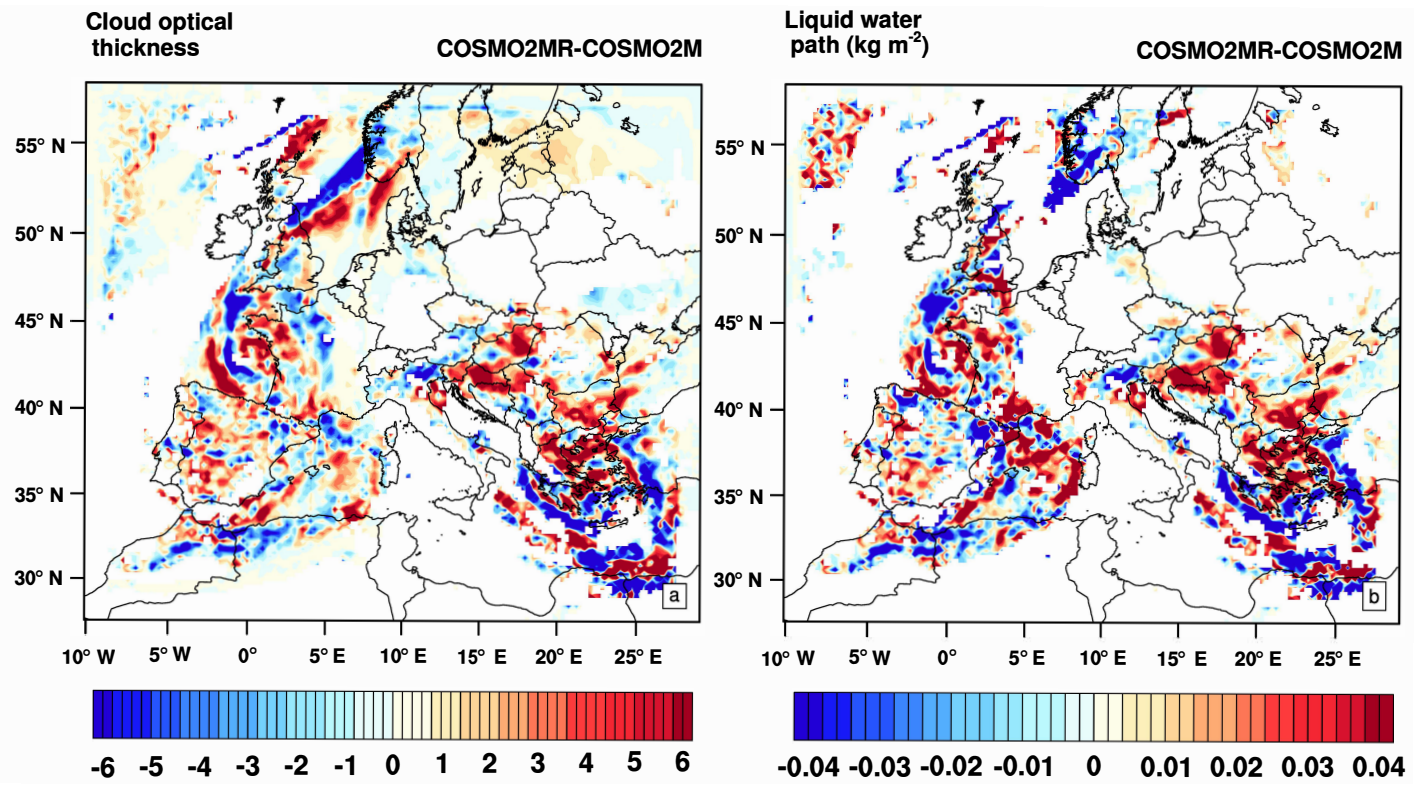

Figure 8. Daily averaged cloud optical depth and liquid water path differences between COSMO2MR and COSMO2M on 17 February 2007.

$26 \mathrm{~W} \mathrm{~m}^{-2}$ and TOA net downward longwave flux varies between -290 and $-140 \mathrm{~W} \mathrm{~m}^{-2}$ (Fig. 9). Additionally, correlations between satellites and models $(\mathrm{COSMO} 2 \mathrm{M}$ and COSMO-MUSCAT; model outputs are regridded to satellite resolution) are illustrated in Fig. 9c and d. The model modifications (revised radiation scheme and interactive aerosols) result in an increase in the correlation coefficient from 0.61 (COSMO2M) to 0.84 (COSMO-MUSCAT) in the case of net shortwave flux at the surface, whereas the modifications do not have much effect on the longwave flux.

\section{Conclusions}

This paper discusses the modification of the Seifert and Beheng (2006) two-moment scheme in the COSMO model. This has been done with aerosol information from the onlinecoupled MUSCAT model, which allows for a microphysical aerosol effect on clouds. It has been achieved by replacing the constant cloud condensation nuclei profile in the COSMO two-moment scheme with gridded aerosol information derived from the online-coupled MUSCAT model, using the Boucher and Lohmann (1995) parameterization, which takes sulfate aerosol as a proxy for all aerosols. In addition, the radiation scheme is revised to a droplet-size-dependent cloud optical depth, allowing now for aerosol-cloud-radiation interactions. In order to facilitate an evaluation using satellite retrievals, the COSP satellite simulator has been incorporated into the modeling system which runs online in the model. The model results are evaluated with satellite observations from the ISCCP, MODIS, and CERES projects and instruments, respectively. Since the cloud microphysics modification has been done for cloud droplet nucleation, the anal- ysis is restricted to the liquid part of clouds in the model, and MODIS level-2 cloud products are screened for liquidphase cloud products. Although the two-moment cloud microphysics and radiation scheme in the COSMO model has been modified, the model was not re-tuned to get reasonable $2 \mathrm{~m}$ temperature or precipitation.

A case study has been carried out to compare the model output with observations. The incorporated COSP satellite simulator serves as a link between model and satellite comparisons. Despite the resolution, the COSP-derived ISCCP cloud fraction shows a similar spatial pattern and magnitude. Further, MODIS level-2 cloud optical products such as cloud optical depth, effective radius, and liquid water path are compared. The COSMO-MUSCAT-derived cloud optical properties show a similar spatial distribution compared to the MODIS observation. In COSMO-MUSCAT, the cloud optical depth has been increased by $4.1 \%$, cloud droplet effective has been increased by $9.5 \%$, and liquid water path has been increased by $14.2 \%$ in comparison to COSMO2M. In turn, the cloud droplet number concentration estimated from the COSMO-MUSCAT model shows a reduction of $21.5 \% \mathrm{com}$ pared to the COSMO2M model. Furthermore, considerable changes in the radiation budget have been found. This analysis indicates that the coupled model (COSMO-MUSCAT) with interactive aerosol treatment results in an increase in cloud droplet size and a reduction in cloud droplet number concentration by activation and growth of droplets, which illustrates implicit aerosol-cloud interactions. Also, the cloud properties in COSMO-MUSCAT agree reasonably well with observations, so that it can be used for regional aerosol-cloud interaction studies. 

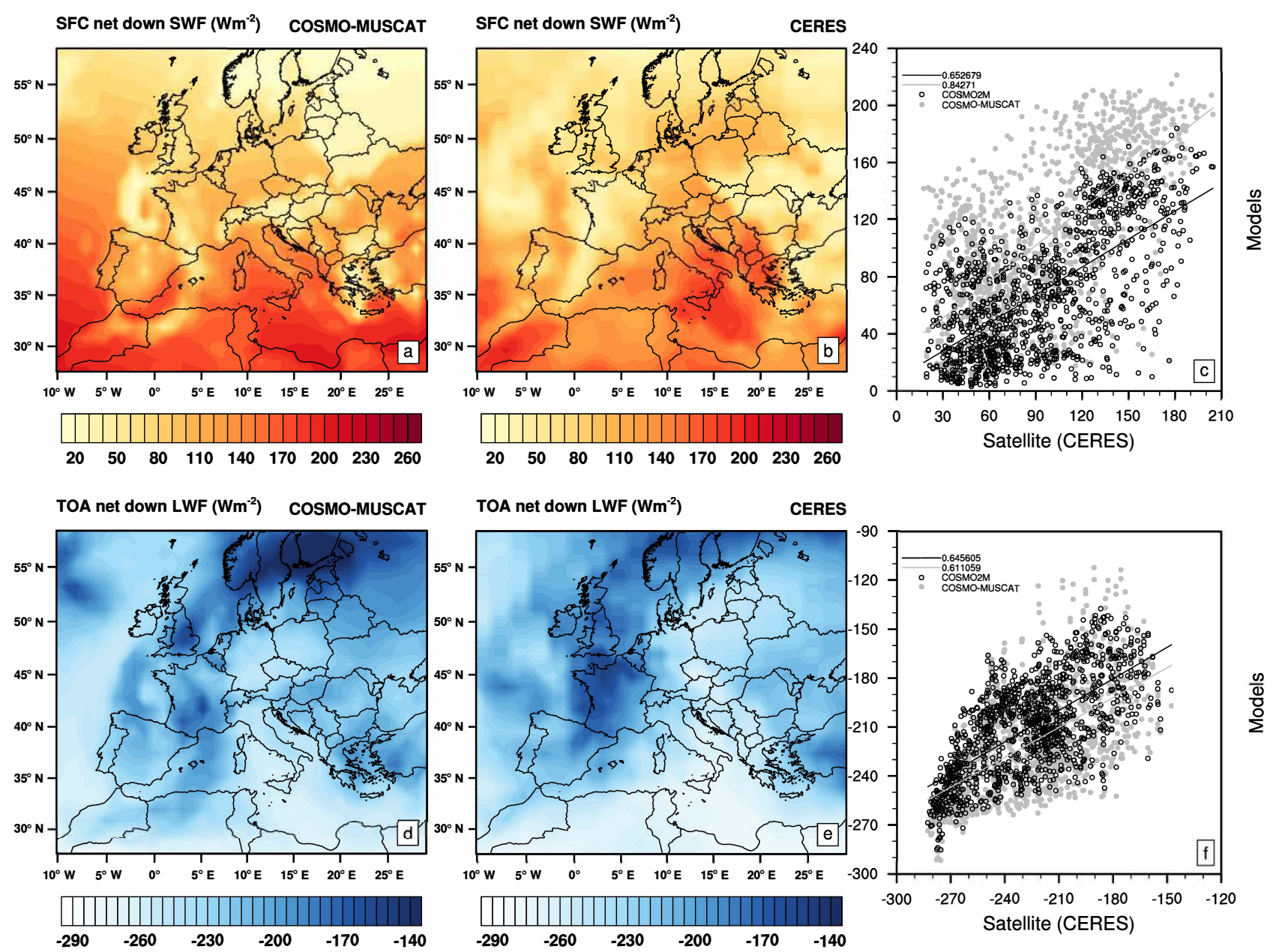

Figure 9. Comparison between shortwave and longwave fluxes at the surface and top of the atmosphere with CERES satellite fluxes and correlation between satellite (CERES) and models (COSMO2MR and COSMO2M).

As a next step, further improvement in the two-moment scheme will be carried out through the use of the newly included aerosol model M7 (Vignati et al., 2004) framework in the MUSCAT model, which is able to provide aerosol number concentration information to the COSMO two-moment scheme by replacing Boucher and Lohmann (1995) parameterization. This can result in more precise cloud droplet activation parameterization, involving different aerosol species such as $C_{\mathrm{ccn}}$, and thus improving the microphysical aerosol effect on clouds (Lohmann et al., 2007). Also, the role of aerosols on ice nucleation will be addressed.

Code and data availability. The COSMO-MUSCAT(5.0) model is freely available under public license policy. The source code, external parameters, and documentation can be obtained through Ralf Wolke (wolke@ tropos.de).
The Supplement related to this article is available online at https://doi.org/10.5194/gmd-10-2231-2017supplement.

Competing interests. The authors declare that they have no conflict of interest.

Acknowledgements. This work was supported by an ERC starting grant "QUAERERE” (GA no. 306284). We acknowledge the development work by the COSMO consortium. We thank Axel Seifert and the anonymous reviewers for their valuable suggestions.

Edited by: J. Williams

Reviewed by: three anonymous referees 


\section{References}

Ackerman, A. S., Toon, O. B., Stevens, D. E., Heymsfield, A. J., Ramanathan, V., and Welton, E. J.: Reduction of Tropical Cloudiness by Soot, American Association for the Advancement of Science, 288, 1042-1047, https://doi.org/10.1126/science.288.5468.1042, 2000.

Ackerman, A. S., Michael, P. K., David, E. S., and Owen, B. T.: The impact of humidity above stratiform clouds on indirect aerosol climate forcing, Nature, 432, 1014-1017, https://doi.org/10.1038/nature03174, 2004.

Baldauf, M., Seifert, A., Förstner, J., Majewski, D., Raschendorfer, M., and Reinhardt, T.: Operational Convective-Scale Numerical Weather Prediction with the COSMO Model: Description and Sensitivities, Mon. Weather Rev., 139, 3887-3905, https://doi.org/10.1175/MWR-D-10-05013.1, 2011.

Bangert, M., Kottmeier, C., Vogel, B., and Vogel, H.: Regional scale effects of the aerosol cloud interaction simulated with an online coupled comprehensive chemistry model, Atmos. Chem. Phys., 11, 4411-4423, https://doi.org/10.5194/acp-114411-2011, 2011.

Beheng, K. D. and Doms, G.: A general formulation of collection rates of cloud and raindrops using the kinetic equation and comparison with parameterizations, Contrib. Atmos. Phys, 59, 6684, 1986.

Berner, A. H., Bretherton, C. S., Wood, R., and Muhlbauer, A.: Marine boundary layer cloud regimes and POC formation in a CRM coupled to a bulk aerosol scheme, Atmos. Chem. Phys., 13, 12549-12572, https://doi.org/10.5194/acp-13-125492013, 2013.

Bodas-Salcedo, A. A., Webb, M. J., Brooks, M. E., Ringer, M. A., William, K. D., Milton, S. F., and Wilson, D. R.: Evaluating cloud systems in the Met Office global forecast model using simulated CloudSat radar reflectivities, J. Geophys. Res.-Atmos., 113, D00A13, https://doi.org/10.1029/2007JD009620, 2008.

Bodas-Salcedo, A. A., Webb, M., Bony, S., Chepfer, H., Dufresne, J., Klein, S., Zhang, Y., Marchand, R., Haynes, J., Pincus, R., and John, V.: COSP: Satellite simulation software for model assessment, B. Am. Meteorol. Soc., 92, 1023-1043, https://doi.org/10.1175/2011BAMS2856.1, 2011.

Boucher, O. and Lohmann, U.: The sulfate-CCN-cloud albedo effect: A sensitivity study with two general circulation models, Tellus B, 47, 281-300, 1995.

Brunke, M. A., de Szoeke, S. P., Zuidema, P., and Zeng, X.: A comparison of ship and satellite measurements of cloud properties with global climate model simulations in the southeast Pacific stratus deck, Atmos. Chem. Phys., 10, 6527-6536, https://doi.org/10.5194/acp-10-6527-2010, 2010.

Chapman, E. G., Gustafson Jr., W. I., Easter, R. C., Barnard, J. C., Ghan, S. J., Pekour, M. S., and Fast, J. D.: Coupling aerosol-cloud-radiative processes in the WRF-Chem model: Investigating the radiative impact of elevated point sources, Atmos. Chem. Phys., 9, 945-964, https://doi.org/10.5194/acp-9945-2009, 2009.

Chepfer, H., Bony, S., Winker, D., Cesana, G., Dufresne, J. L., Minnis, P., Stubenrauch, C. J., and Zeng, S.: The GCM oriented CALIPSO cloud product (CALIPSOGOCCP), J. Geophys. Res.-Atmos., 115, D00H16, https://doi.org/10.1029/2009JD012251, 2010.
Cherian, R., Venkataraman, C., Ramachandran, S., Quaas, J., and Kedia, S.: Examination of aerosol distributions and radiative effects over the Bay of Bengal and the Arabian Sea region during ICARB using satellite data and a general circulation model, Atmos. Chem. Phys., 12, 1287-1305, https://doi.org/10.5194/acp12-1287-2012, 2012

Cotton, W. R., Tripoli, G. P., Rauber, R. M., and Mulvihill, E. A.: Numerical simulation of the effects of varying ice crystal nucleation rates and aggregation processes on orographic snowfall, J. Clim. Appl. Meteorol., 25, 1658-1680, https://doi.org/10.1175/1520 0450(1986)025<1658:NSOTEO>2.0.CO;2, 1986.

Doms, G. and Schättler, U.: The Nonhydrostatic Limited-Area Model LM (Lokal-Modell) of DWD: Part I: ScientificDocumentation (Version LM-F90 1.35), Deutscher Wetterdienst, Offenbach, Germany, 1999.

Forkel, R., Balzarini, A., Baró, R., Bianconi, R., Curci, G., Jiménez-Guerrero, P., Hirtl, M., Honzak, L., Lorenz, C., Im, U., J. L. Pérez, G. P., José, R. S., Tuccella, P., Werhahn, J.,

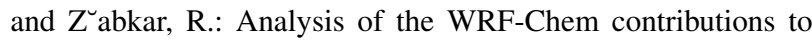
AQMEII phase 2 with respect to aerosol radiative feedbacks on meteorology and pollutant distributions, Atmos. Environ., 115, 630-645, https://doi.org/10.1016/j.atmosenv.2014.10.056, 2015.

Ghan, S., Wang, M., Zhang, S., Ferrachat, S., Gettelman, A., Griesfeller, J., Kipling, Z., Lohmann, U., Morrison, H., Neubauer, D., Partridge, D. G., Stier, P., Takemura, T., Wang, H., and Zhang, K.: Challenges in constraining anthropogenic aerosol effects on cloud radiative forcing using present-day spatiotemporal variability, P. Natl. Acad. Sci. USA, 113, 580-5811, https://doi.org/10.1073/pnas.1514036113, 2016.

Guo, S., Henry, L., and Murray, M.: Surface-Absorbed and Topof-Atmosphere Radiation Fluxes for the Mackenzie River Basin from Satellite Observations and a Regional Climate Model and an Evaluation of the Model, Canadian Meteorological and Oceanographic Society, 45, 129-139, 2007.

IPCC: Climate change 2013: The physical science basis. Contribution of working group I to the fifth assessment report of the Intergovernmental Panel on Climate Change, edited by: Stocker, T. F., Qin, D., Plattner, G.-K., Tignor, M., Allen, S. K., Boschung, J., Nauels, A., Xia, Y., Bex, V., and Midgley, P. M., Cambridge University Press, Cambridge, UK and New York, NY, USA, 1535 pp., https://doi.org/10.1017/CBO9781107415324, 2013.

Kato, S. and Loeb, N. G.: Twilight irradiance reflected by the Earth estimated from Clouds and the Earth's Radiant Energy System (CERES) measurements, J. Climate, 16, 2649-2650, https://doi.org/10.1175/15200442(2003)016<2646:TIRBTE>2.0.CO;2, 2003.

Kessler, E.: On the distribution and continuity of water substance in atmospheric circulations, Am. Meteorol. Soc., 10, 1-84, https://doi.org/10.1007/978-1-935704-36-2_1, 1969.

Khain, A., Ovtchinnikov, M., Pinsky, M., Pokrovsky, A., and Krugliak, H.: Notes on the state-of-the-art numerical modeling of cloud microphysics, Atmos. Res., 55, 159-224, https://doi.org/10.1016/S0169-8095(00)00064-8, 2000.

Khain, A. P., Rosenfeld, D., and Pokrovsky, A.: Simulating convective clouds with sustained supercooled liquid water down to $-37.5^{\circ} \mathrm{C}$ using a spectral microphysics model, Geophys. Res. Lett., 28, 3887-3890, https://doi.org/10.1029/2000GL012662, 2001. 
Li, G., Wang, Y., and Zhang, R.: Implementation of a twomoment bulk microphysics scheme to the WRF model to investigate aerosol-cloud interaction, J. Geophys. Res.-Atmos., 113, D15211, https://doi.org/10.1029/2007JD009361, 2008.

Lim, K. and Hong, S.: Development of an effective doublemoment cloud microphysics scheme with prognostic cloud condensation nuclei $(\mathrm{CCN})$ for weather and climate models, Mon. Weather Rev., 138, 1587-1612, https://doi.org/10.1175/2009MWR2968.1, 2010.

Lin, Y. L., Farley, R. D., and Orville, H.: Bulk parameterization of the snow field in a cloud model, J. Clim. Appl. Meteorol., 22, 1065-1092, https://doi.org/10.1175/15200450(1983)022<1065:BPOTSF>2.0.CO;2, 1983.

Loeb, N. G., Lyman, J. M., Johnson, G. C., Allan, R. P., Doelling, D. R., Wong, T., Soden, J., and Stephens, G. L.: Observed changes in top- of-the-atmosphere radiation and upper-ocean heating consistent within uncertainty, Nat. Geosci., 5, 110-113, https://doi.org/10.1038/ngeo1375, 2012.

Lohmann, U., Stier, P., Hoose, C., Ferrachat, S., Kloster, S., Roeckner, E., and Zhang, J.: Cloud microphysics and aerosol indirect effects in the global climate model ECHAM5-HAM, Atmos. Chem. Phys., 7, 3425-3446, https://doi.org/10.5194/acp-7-34252007, 2007.

Majewski, D., Liermann, D., Prohl, P., Ritter, B., Buchhold, M., Hanisch, T., Paul, G., Wergen, W., and Baumgardner, J.: The operational global Icosahedral-Hexagonal Gridpoint Model GME: description and high-resolution tests, Mon. Weather Rev., 130, 319-338, https://doi.org/10.1175/15200493(2002)130<0319:TOGIHG>2.0.CO;2, 2002.

Marchand, R., Haynes, J., Mace, G. G., Ackerman, T., and Stephens, G.: A comparison of simulated cloud radar output from the multiscale modeling framework global climate model with CloudSat cloud radar observations, J. Geophys. Res.-Atmos., 114, D00A20, https://doi.org/10.1029/2008JD009790, 2009.

Martin, G. M., Johnson, D. W., and Spice, A. A.: The measurement and parameterization of effective radius of droplets in the warm stratocumulus clouds, J. Atmos. Sci., 51, 1823-1842, https://doi.org/10.1175/15200469(1994)051<1823:TMAPOE>2.0.CO;2, 1994.

Meyers, M. P., Walko, R. L., Harrington, J. Y., and Cotton, W. R.: New RAMS cloud microphysics parameterization: Part II: The two-moment scheme, Atmos. Res., 45, 3-39, https://doi.org/10.1016/S0169-8095(97)00018-5, 1997.

Min, Q., Joseph, E., Lin, Y., Min, L., Yin, B., Daum, P. H., Kleinman, L. I., Wang, J., and Lee, Y.-N.: Comparison of MODIS cloud microphysical properties with in-situ measurements over the Southeast Pacific, Atmos. Chem. Phys., 12, 11261-11273, https://doi.org/10.5194/acp-12-11261-2012, 2012.

Morrison, H. and Gettelman, A.: A new two-moment bulk stratiform cloud microphysics scheme in the community atmosphere model, Version 3 (CAM3). Part I: Description and numerical tests, J. Climate, 21, 3642-3659, https://doi.org/10.1175/2008JCLI2105.1, 2008.

Morrison, H., Thompson, G., and Tatarskii, V.: Impact of cloud microphysics on the development of trailing stratiform precipitation in a simulated squall line: Comparison of one and two-moment schemes, Mon. Weather Rev., 137, 991-1007, https://doi.org/10.1175/2008MWR2556.1, 2009.
Mühlbauer, A., Berry, E., Comstock, J. M., and Mace, G. G.: Perturbed physics ensemble simulations of cirrus on the cloud system-resolving scale, J. Geophys. Res.-Atmos., 119, 47094735, https://doi.org/10.1002/2013JD020709, 2014.

Mühlbauer, A., Ackerman, T. P., Lawson, R. P., Xie, S., and Zhang, Y.: Evaluation of cloud-resolving model simulations of midlatitude cirrus with ARM and A-train observations, J. Geophys. Res.-Atmos., 120, 6597-6618, https://doi.org/10.1002/2014JD022570, 2015.

Nam, C. and Quaas, J.: Evaluation of clouds and precipitation in the ECHAM5 general circulation model using CALIPSO and CloudSat, J. Climate, 25, 4975-4992, https://doi.org/10.1175/JCLI-D11-00347.1, 2012.

Nam, C., Quaas, J., Neggers, R., Drian, C. S.-L., and Isotta, F.: Evaluation of boundary layer cloud parameterizations in the ECHAM5 general circulation model using CALIPSO and CloudSat satellite data, J. Adv. Model. Earth Syst., 6, 300-314, https://doi.org/10.1002/2013MS000277, 2014.

Noble, S. R. and Hudson, J. G.: MODIS comparisons with northeastern Pacific in situ stratocumulus microphysics, J. Geophys. Res.-Atmos., 120, 8332-8344, https://doi.org/10.1002/2014JD022785, 2015.

Penner, J. E., Andreae, M. O., Annegarn, H., Barrie, L., Feichter, J., Hegg, D., Jayaraman, A., Leaitch, R., Murphy, D., Nganga, J., and Pitari, G.: Aerosols, their Direct and Indirect Effects, in: Climate Change 2001: The Scientific Basis, Contribution of working group I to the Third Assessment Report of the Intergovernmental Panel on Climate Change, edited by: Houghton, J. T., Ding, Y., Griggs, D. J., Noguer, M., Van der Linden, P. J., Dai, X., Maskell, K., and Johnson, C. A., Cambridge University Press, New York, USA, 289-348, 2001.

Penner, J. E., Quaas, J., Storelvmo, T., Takemura, T., Boucher, O., Guo, H., Kirkevåg, A., Kristjánsson, J. E., and Seland, Ø.: Model intercomparison of indirect aerosol effects, Atmos. Chem. Phys. 6, 3391-3405, https://doi.org/10.5194/acp-6-3391-2006, 2006.

Pincus, R., Platnick, S., Ackerman, S. A., Hemler, R. S., and Hofmann, R. J. P.: Reconciling simulated and observed views of clouds: MODIS, ISCCP, and the limits of instrument simulators, J. Climate, 25, 4699-4720, https://doi.org/10.1175/JCLI-D-1100267.1, 2012.

Platnick, S., Li, J. Y., King, M. D., Gerber, H., and Hobbs, P. V.: A solar reflectance method for retrieving the optical thickness and droplet size of liquid water clouds over snow and ice surfaces, J. Geophys. Res.-Atmos., 106, 15185-15199, https://doi.org/10.1029/2000JD900441, 2001.

Platnick, S., King, M. D., Ackerman, S. A., Menzel, W. P., Baum, B. A., Riedi, J. C., and Frey, R. A.: The MODIS cloud products: Algorithms and examples from Terra, IEEE T. Geosci. Remote, 41, 459-473, https://doi.org/10.1109/TGRS.2002.808301, 2003.

Possner, A., Zubler, E., Lohmann, U., and Schär, C.: Realcase simulations of aerosol-cloud interactions in ship tracks over the Bay of Biscay, Atmos. Chem. Phys., 15, 2185-2201, https://doi.org/10.5194/acp-15-2185-2015, 2015.

Pouliot, G., Pierce, T., Denier van der Gon, H., Schaap, M., Moran, M., and Nopmongcol, U.: Comparing emissions inventories and model-ready emissions datasets between Europe and North America for the AQMEII project, Atmos. Environ., 53, 414, https://doi.org/10.1016/j.atmosenv.2011.12.041, 2012. 
Quaas, J., Boucher, O., and Bréon, F. M.: Aerosol indirect effects in POLDER satellite data and in the Laboratoire de Météorologie Dynamique-Zoom (LMDZ) general circulation model, J. Geophys. Res.-Atmos., 109, D08205, https://doi.org/10.1029/2003JD004317, 2004.

Quaas, J., Boucher, O., and Lohmann, U.: Constraining the total aerosol indirect effect in the LMDZ and ECHAM4 GCMs using MODIS satellite data, Atmos. Chem. Phys., 6, 947-955, https://doi.org/10.5194/acp-6-947-2006, 2006.

Quaas, J., Ming, Y., Menon, S., Takemura, T., Wang, M., Penner, J. E., Gettelman, A., Lohmann, U., Bellouin, N., Boucher, O., Sayer, A. M., Thomas, G. E., McComiskey, A., Feingold, G., Hoose, C., Kristjánsson, J. E., Liu, X., Balkanski, Y., Donner, L. J., Ginoux, P. A., Stier, P., Grandey, B., Feichter, J., Sednev, I., Bauer, S. E., Koch, D., Grainger, R. G., Kirkevåg, A., Iversen, T., Seland, Ø., Easter, R., Ghan, S. J., Rasch, P. J., Morrison, H., Lamarque, J.-F., Iacono, M. J., Kinne, S., and Schulz, M.: Aerosol indirect effects - general circulation model intercomparison and evaluation with satellite data, Atmos. Chem. Phys., 9, 8697-8717, https://doi.org/10.5194/acp-9-8697-2009, 2009.

Reisner, J., Rasmussen, R. M., and Bruintjes, R. T.: Explicit forecasting of supercooled liquid water in winter storms using the MM5 mesoscale model, Q. J. Roy. Meteor. Soc., 124, 10711107, https://doi.org/10.1002/qj.49712454804, 1998.

Renner, E. and Wolke, R.: Modelling the formation and atmospheric transport of secondary inorganic aerosols with special attention to regions with high ammonia emissions, Atmos. Environ., 44, 1904-1912, https://doi.org/10.1016/j.atmosenv.2010.02.018, 2010.

Ritter, B. and Geleyn, J.: A comprehensive radiation scheme for numerical weather prediction models with potential applications in climate simulations, Mon. Weather Rev., 120, 303-325, https://doi.org/10.1175/15200493(1992)120<0303:ACRSFN>2.0.CO;2, 1992.

Rossow, W. B. and Schiffer, R. A.: Advances in understanding clouds from ISCCP, B. Am. Meteorol. Soc., $\quad 80, \quad 2261-2287$, https://doi.org/10.1175/15200477(1999)080<2261:AIUCFI>2.0.CO;2, 1999.

Sandu, I., J. L., B., Geoffroy, O., Thouron, O., and Masson, V.: Aerosol impacts on the diurnal cycle of marine stratocumulus, J. Atmos. Sci., 65, 2705-2718, https://doi.org/10.1175/2008JAS2451.1, 2008.

Seifert, A. and Beheng, K. D.: A double-moment parameterization for simulating autoconversion, accretion and selfcollection, Atmos. Res., 59-60, 265-281, https://doi.org/10.1016/S01698095(01)00126-0, 2001

Seifert, A. and Beheng, K. D.: A two-moment cloud microphysics parameterization for mixed- phase clouds. Part 1: Model description, Meteorol. Atmos. Phys., 92, 45-66, https://doi.org/10.1007/s00703-005-0112-4, 2006.

Seifert, A., Köhler, C., and Beheng, K. D.: Aerosol-cloudprecipitation effects over Germany as simulated by a convectivescale numerical weather prediction model, Atmos. Chem. Phys., 12, 709-725, https://doi.org/10.5194/acp-12-709-2012, 2012.

Seifert, A., Heus, T., Pincus, R., and Stevens, B.: Large-eddy simulation of the transient and near-equilibrium behavior of precipitating shallow convection, J. Adv. Model. Earth Syst., 7, 1942 2466, https://doi.org/10.1002/2015MS000489, 2015.
Simmel, M., Bühl, J., Ansmann, A., and Tegen, I.: Ice phase in altocumulus clouds over Leipzig: remote sensing observations and detailed modeling, Atmos. Chem. Phys., 15, 10453-10470, https://doi.org/10.5194/acp-15-10453-2015, 2015.

Sourdeval, O., C.-Labonnote, L., Baran, A. J., Mülmenstädt, J., and Brogniez, G.: A methodology for simultaneous retrieval of ice and liquid water cloud properties. Part 2: Near-global retrievals and evaluation against A-Train products, Q. J. Roy. Meteor. Soc., 142, 3063-3081, https://doi.org/10.1002/qj.2889, 2016.

Steppeler, J., Doms, G., Schüttler, U., Bitzer, H. W., Gassmann, A., Damrath, U., and Gregoric, G.: Meso-gamma scale forecasts using the nonhydrostatic model LM, Meteorol. Atmos. Phys., 82, 75-96, https://doi.org/10.1007/s00703-001-0592-9, 2003.

Stevens, B. and Feingold, G.: Untangling aerosol effects on clouds and precipitation in a buffered system, Nature, 461, 607-613, https://doi.org/10.1038/nature08281, 2009.

Stockwell, W. R., Kirchner, F., Kuhn, M., and Seefeld, S.: A new mechanism for regional atmospheric chemistry modeling, J. Geophys. Res.-Atmos., 102, 25847-25879, https://doi.org/10.1029/97JD00849, 1997.

Storelvmo, T., Lohmann, U., and Bennartz, R.: What governs the spread in shortwave forcings in the transient IPCC AR4 models?, Geophys. Res. Lett., 36, L01806, https://doi.org/10.1029/2008GL036069, 2009.

Tao, W.-K., Simpson, J., Baker, D., Braun, S., Chou, M. D., Ferrier, B., Johnson, D., Khain, A., Lang, S., Lynn, B., Shie, C. L., Starr, D., Sui, C. H., Wang, Y., and Wetzel, P.: Microphysics, radiation and surface processes in the Goddard $\mathrm{Cu}$ mulus Ensemble (GCE) model, Atmos. Res., 143, 392-424, https://doi.org/10.1016/j.atmosres.2014.03.005, 2003.

Thompson, G., Field, P. R., Rasmussen, R. M., and Hall, W. D.: Explicit forecasts of winter precipitation using an improved bulk microphysics scheme. part II: Implementation of a new snow parameterization, Mon. Weather Rev., 136, 5095-5115, https://doi.org/10.1175/2008MWR2387.1, 2008.

Van den Heever, S. C. and Cotton, W. R.: Urban aerosol impacts on downwind convective storms, J. Appl. Meteorol. Clim., 46, 828-850, https://doi.org/10.1175/JAM2492.1, 2007.

Vignati, E., Wilson, J., and Stier, P.: M7: An efficient sizeresolved aerosol microphysics module for large-scale aerosol transport models, J. Geophys. Res.-Atmos., 109, D22202, https://doi.org/10.1029/2003JD004485, 2004.

Weverberg, V. K., Goudenhoofdt, E., Blahak, U., Brisson, E., Demuzere, M., Marbaix, P., and van Ypersele, J. P.: Comparison of one-moment and two-moment bulk microphysics for high-resolution climate simulations of intense precipitation, Atmos. Res., 147-148, 145-161, https://doi.org/10.1016/j.atmosres.2014.05.012, 2014.

Wolke, R., Knoth, O., Hellmuth, O., Schröder, W., and Renner, E.: The parallel model system LM-MUSCAT for chemistry-transport simulations: Coupling scheme, parallelization and application, in: Parallel Computing: Software Technology, Algorithms, Architectures, and Applications, edited by: Joubert, G. R., Nagel, W. E., Peters, F. J., and Walter, W. V., Elsevier, Amsterdam, the Netherlands, 363-370, https://doi.org/10.1016/S0927-5452(04)80048-0, 2004.

Wolke, R., Schröder, W., Schrödner, R., and Renner, E.: Influence of grid resolution and meteorological forcing on simulated European air quality: a sensitivity study with the model- 
ing system COSMO-MUSCAT, Atmos. Environ., 53, 110-130, https://doi.org/10.1016/j.atmosenv.2012.02.085, 2012.

Xue, H. and Feingold, G.: Large eddy simulations of trade-wind cumuli:Investigation of aerosol indirect effects, J. Atmos. Sci., 63, 1605-1622, https://doi.org/10.1175/JAS3706.1, 2006.

Yang, Q., Gustafson Jr., W. I., Fast, J. D., Wang, H., Easter, R. C., Wang, M., Ghan, S. J., Berg, L. K., Leung, L. R., and Morrison, H.: Impact of natural and anthropogenic aerosols on stratocumulus and precipitation in the Southeast Pacific: a regional modelling study using WRF-Chem, Atmos. Chem. Phys., 12, 87778796, https://doi.org/10.5194/acp-12-8777-2012, 2012.

Zhang, M. H., Lin, W. Y., Klein, S. A., Bacmeister, J. T., Bony, S., Cederwall, R. T., Del Genio, A. D., Hack, J. J., Loeb, N. G., Lohmann, U., Minnis, P., Musat, I., Pincus, R., Stier, P., Suarez, M. J., Webb, M. J., Wu, J. B., Xie, S. C., Yao, M.-S., and Zhang, J. H.: Comparing clouds and their seasonal variations in 10 atmospheric general circulation models with satellite measurements, J. Geophys. Res.-Atmos., 110, D15S02, https://doi.org/10.1029/2004JD005021, 2005.
Zhang, Y., Karamchandani, P., Glotfelty, T., Streets, D. G., Grell, G., Nenes, A., Yu, F., and Bennartz, R.: Development and initial application of the global-through-urban weather research and forecasting model with chemistry (GU-WRF/Chem), J. Geophys. Res.-Atmos., 117, D20206, https://doi.org/10.1029/2012JD017966, 2012.

Zhang, Z., Ackerman, A. S., Feingold, G., Platnick, S., Pincus, R., and Xue, H.: Effects of cloud horizontal inhomogeneity and drizzle on remote sensing of cloud droplet effective radius: Case studies based on large-eddy simulations, J. Geophys. Res.Atmos., 117, D19208, https://doi.org/10.1029/2012JD017655, 2012.

Zubler, E. M., Folini, D., Lohmann, U., Lüthi, D., Mühlbauer, A., Pousse-Nottelmann, S., Schär, C., and Wild, M.: Implementation and evaluation of aerosol and cloud microphysics in a regional climate model, J. Geophys. Res.-Atmos., 116, D02211, https://doi.org/10.1029/2010JD014572, 2011. 